\title{
LOS PROBLEMAS DEL VELLÓN \\ EN EL SIGLO XVII. ¿SE CONSIGUIÓ \\ ABARATAR LA NEGOCIACIÓN \\ DEL CRÉDITO IMPONIENDO \\ PRECIOS MÁXIMOS A LA PLATA?
}

\author{
CARLOS ÁLVAREZ NOGAL * \\ Universidad Carlos III/Stanford University
}

\section{RESUMEN}

Este trabajo pretende analizar los resultados de la regulación del tipo de cambio vellón-plata sobre la contratación del crédito a corto plazo de la Real Hacienda, comparando los tipos máximos oficiales con los que fueron fijados en los contratos con los banqueros en la primera mitad del siglo xva. Para ello emplearemos los conceptos que nos brinda la teoría de regulación de precios y del funcionamiento de los mercados negros. Este trabajo pone de manifiesto que la regulación no sirvió para abaratar el valor del metal precioso y que la Corona tuvo que pagar por la plata lo que realmente valía. Sin embargo, influyó sobre la estrategia adoptada por los agentes financieros en los mercados.

\section{ABSTRACT}

The purpose of this paper is to analyze the effects of the control of the exchange rate vellón-silver over the prices in the Castile Crown's short-run credit. It compares the official price rates with the prices signed in the credit contracts of foreign financiers during the first half of the XVI century. The paper uses concepts from the price control theory and research done on black markets. There are many evidences that suggest that the official rates did not work to control the price of precious metals. In fact, the Crown had to

* El autor agradece las valiosas sugerencias que ha recibido de José I. García de Paso, Gabriel Tortella, Ángel García Sanz y Elena M." García Guerra, así como las críticas y comentarios de los evaluadores anónimos de la Revista de Historia Económica. Una versión de este trabajo fue presentada en los seminarios de la Universidad Internacional Menéndez Pelayo y de la Università di Pavia (Italia). Este trabajo es fruto de una investigación financiada con ayuda de la DGYCIT (Proyecto: PS98-0686), y de la Dirección General de Investigación Cientifica durante mi estancia en el Social Science History Institute (Stanford University). 
pay the costly real price of the silver when it needed. Nevertheless, this policy served to change the behaviour of the financiers in the markets.

\section{INTRODUCCIÓN}

La manipulación de la moneda ha sido un recurso comúnmente empleado por las diferentes Monarquías a lo largo de la historia para cubrir sus déficit presupuestarios ${ }^{1}$. Varios trabajos se han encargado de analizar los problemas derivados de esta práctica en Castilla a lo largo del siglo XvII poniendo de manifiesto los hitos legislativos de la acuñación o resello de moneda, el cálculo de las cantidades emitidas y estimando la inflación provocada sobre el metal precioso y el resto de los bienes de consumo ${ }^{2}$. Recientemente, se ha avanzado en la explicación de los mecanismos monetarios de dicho proceso y el impacto que tuvieron los intentos de reforma ${ }^{3}$. Sin embargo, apenas se han estudiado los efectos que tuvo la manipulación de dicha moneda sobre la negociación crediticia de la Corona, siendo éste el objetivo prioritario de la Monarquía y la razón de ser de la moneda de cobre. Este trabajo pretende analizar los resultados de la regulación del tipo de cambio vellón-plata sobre la contratación del crédito a corto plazo de la Real Hacienda, comparando los tipos máximos oficiales con los que fueron fijados en los contratos con los banqueros extranjeros en la primera mitad del siglo xvI. La principal fuente de nuestro análisis son las consultas del Consejo de Hacienda conservadas en el Archivo General de Simancas, donde se recogen los términos de la negociación de los contratos de crédito. También emplearemos los conceptos que nos brinda la teoría de regulación de precios y del funcionamiento de los mercados negros.

Una de las soluciones de la Corona para controlar la inflación que causó el vellón en la economía castellana consistió en una serie de pragmáticas dirigidas a mantener el precio de la plata por debajo de su valor real en términos de moneda de cobre ${ }^{4}$. Ese empeño por fijar oficialmente el precio del cambio vellón-plata pretendía evitar que el encarecimiento del metal precioso impidiese la negociación crediticia y, por lo tanto, su

${ }^{1}$ Parker (1974), p. 529; Spooner (1972), pp. 22-29, y Sussman (1993), pp. 44-70.

2 Hamilton (1983) y (1984), pp. 59-102; Domínguez Ortiz (1960); Serrano Mangas (1996); Collantes y Merino (1977), pp. 73-98; Motomura (1994), pp. 104-127, y (1997), pp. 331-367, y García Guerra (1999).

${ }^{3}$ García de Paso (2000a), p. 57, (1999) y (2000b).

${ }^{4}$ Hamilton (1984), pp. 93-96. 
política exterior. La Corona había obtenido beneficios al introducir la moneda de cobre puro por la diferencia entre el coste de producción (o valor intrínseco) y el valor nominal con que la ponía en circulación, y también intentó beneficiarse al controlar los efectos inflacionistas fijando el cambio, aunque en este caso los resultados no fueron igual de satisfactorios. Los trabajos de Hamilton y Serrano Mangas sobre los premios de la plata ponen de manifiesto el fracaso de las pragmáticas de regulación para contener el precio del metal precioso en el mercado ${ }^{5}$. Los particulares hicieron caso omiso de las prohibiciones y la plata se cambió a precios de mercado. ¿Ocurrió lo mismo en el ámbito financiero donde la Corona estaba presente? ¿Consiguió con ello la Corona abaratar el precio de sus provisiones en plata?

\section{EL VELLÓN EN LAS FINANZAS DE LA MONARQUÍA ¿SOLUCIÓN O PROBLEMA?}

Tanto Carlos V como Felipe II habían acuñado vellón para cubrir la necesidad de moneda que tenían las pequeñas transacciones comerciales, más que para tratar de solucionar sus problemas de liquidez. Sin embargo, durante el reinado de Felipe III la moneda de cobre se convirtió en un instrumento de la Real Hacienda para incrementar sus medios de pago ${ }^{6}$. El acelerado envilecimiento de la moneda desbordó muy pronto los límites de su aceptación. Mientras la presencia de cobre en el mercado no había sido excesiva, se respetó el valor nominal de la ceca, pero en cuanto se multiplicó la oferta, el vellón fue rechazado por el público, aumentando su velocidad de circulación. Para canjearlo por plata fue necesario pagar un precio suplementario al que se denominó «premio», y cuyo valor fue establecido por la ley de la oferta y la demanda.

A la abundante entrada de cobre, debemos sumar también los efectos de la constante salida de metal precioso de Castilla, tanto por parte de la Real Hacienda como de los particulares ${ }^{7}$. Al no circular el vellón fuera de Castilla, los hombres de negocios obtenían todos los años permiso de la Corona para exportar plata con la que cumplir sus compromisos en el extranjero. Esa continua exportación contrarrestaba la entrada del metal

\footnotetext{
'Serrano Mangas (1996), pp. 54-135.

- Motomura (1994), pp. 118-119, y (1997), p. 343; García Guerra (1999), pp. 18-53.

7 Desde el punto de vista comercial, Occidente tenía un déficit persistente en su balanza de pagos con el Báltico y Oriente que debía saldar con oro y plata. Miskimin (1977), p. 149.
} 
precioso americano y alteraba continuamente el difícil equilibrio cambiario que existía entre ambos metales ${ }^{8}$. Castilla no podía en el siglo xvI pagar sólo con manufacturas o materias primas el déficit que generaba su gasto bélico en Europa. Lo que al principio había supuesto un alivio financiero para la Real Hacienda, pues acuñar cobre había sido fácil y enormemente rentable, se convirtió pronto en uno de los mayores problemas de la economía castellana y de la propia Corona ${ }^{9}$.

Los ingresos fiscales que antes se percibian en plata empezaron a recaudarse en vellón, pues los oficiales reales no podían negarse a aceptar esa moneda al valor facial. De esta forma, la mayor parte del ingreso en las arcas reales empezó a ser cobre, y a medida que perdía valor con respecto al metal precioso, se reducía su valor real. Sin embargo, la mayor parte del gasto de la Monarquía siguió concentrándose en el exterior, donde era necesario seguir pagando con metal precioso. Por lo tanto, tras unos primeros años en los que la Corona disfrutó de un ingreso de carácter extraordinario, permitiéndole resolver rápidamente sus problemas de liquidez, empezó pronto a notar directamente los perjuicios de la desproporcionada abundancia de vellón y su acelerada depreciación en los mercados. Ya en 1626, el Consejo de Hacienda explicaba al Rey el engaño que, a largo plazo, había supuesto la ausencia de rigor monetario:

«Y no engañe el socorro que el vellón haze quando se labra, qual es, de no dinero hacer dinero, porque al mismo tiempo que entra éste por la parte que socorre, sale el otro, por el medio de la reducción» ${ }^{10}$.

Entendiendo por reducción, el daño que se sufría al cambiar el vellón por plata pagando su verdadero precio. Muy pronto se hizo patente que la moneda de vellón se había convertido en el caballo de Troya de las finanzas de la Monarquía Hispánica y que era necesario intervenir. El problema fue que la intervención se llevó a cabo sobre el mercado, y no sobre las causas estructurales que hacían el metal precioso más caro en términos de vellón.

\footnotetext{
${ }^{8}$ Ulloa (1975), pp. 459-477; Ruiz Martín (1990), pp. 21-22 y pp. 35-36.

Domínguez Ortiz (1960), p. 239.

10 Archivo General de Simancas (AGS), CJH, 622. Consulta, 5 de abril de 1626.
} 


\section{LOS EFECTOS DE LA INFLACIÓN DEL VELLÓN SOBRE LA NEGOCIACIÓN CREDITICIA}

De todos los perjuicios que causó la inflación del vellón, uno de los más difíciles de asumir por la Real Hacienda fue precisamente el problema que planteó esa moneda en la negociación crediticia con los grandes banqueros. Los servicios que éstos prestaban eran esenciales por su eficaz red de transferencia de fondos entre las principales plazas europeas. Muchas veces se ha tendido a relacionar la presencia de los banqueros sólo con la necesidad de pedir prestado por falta de liquidez, lo cual es parcialmente cierto y bastante equívoco en el caso de la Monarquía Hispánica. Los banqueros, más que dinero, suministraban servicios financieros insustituibles ${ }^{11}$. La Corona, consciente de que tenía garantizados sus ingresos a medio y largo plazo, diseñó siempre su presupuesto de gastos en un escenario de permanente endeudamiento.

Sin embargo, la tendencia al alza del premio de la plata suponía una reducción del valor de las consignaciones en vellón que recibían los banqueros como retorno de sus créditos, pues el valor de lo ofrecido inicialmente por el Consejo de Hacienda no era lo que después obtenían al cambiar la moneda de cobre en el mercado. Además del cambio, había que añadir los costes en tiempo y gestión, pues era necesario encontrar al cambiador, negociar un precio, disponer de información adecuada, contar la moneda, encargarse del transporte, gastar tiempo en todas estas operaciones y asumir toda una multitud de incidencias. Los financieros tampoco podían arriesgarse a aceptar una cantidad de vellón que no estuviesen seguros de poder cambiar. Esos costes de transacción, algunos no monetarios, fueron aumentando al crecer la distancia entre el valor de las monedas de cobre y plata, y añadieron incertidumbre al cumplimiento del contrato de crédito por parte de la Corona.

Si antes se podía negociar un asiento, sin preocuparse por el valor de la moneda castellana, a partir de entonces fue necesario añadir un nuevo capítulo a la negociación: el precio del cambio de moneda y los plazos para llevarlo a cabo. Cuanto más difícil fuese estimar y fijar ese coste, más complicado se hacía llegar a un acuerdo, con lo que las negociaciones tendían a alargarse. Sin embargo, cualquier retraso en la firma de las provisiones suponían un grave perjuicio para la Real Hacienda, pues su dilación acarreaba retrasos en el pago de los ejércitos y en la contratación de lo

\footnotetext{
11 Álvarez Nogal (1999a), p. 23.
} 
necesario para mantener una campaña. Los créditos debían estar firmados en las fechas establecidas anualmente para no interrumpir los ritmos propios de los preparativos militares. La estrategia en las negociaciones enfrentó la postura de cada una de las partes en función de sus intereses. Los hombres de negocios presionaron para evitar un compromiso sobre precios fijos en el cambio. No sólo porque, como se demostró, las expectativas del precio de la plata eran siempre al alza, con lo que, aunque consiguiesen un buen precio, el retraso habitual en la percepción de las consignaciones provocaba siempre su depreciación; sino también porque muchos de ellos no estaban tratando de especular con la moneda. El principal objetivo de los genoveses era acceder al metal precioso cuanto antes para negociar con él en las ferias de cambio italianas. La Real Hacienda intentó evitar que los banqueros estableciesen el precio de la plata según su valor real, con el fin de no pagar ella los efectos de la inflación del vellón, ni tener que soportar los precios especulativos propios de la necesidad del cambio. Además, la tendencia al alza del premio obligó a la Corona a elegir los momentos en los que éste bajaba para entablar negociaciones con sus banqueros, reduciendo su capacidad de negociación y los recursos de que disponía ${ }^{12}$.

Uno de los primeros efectos del vellón fue la huida de algunos de los agentes que hasta entonces intervenían en las negociaciones. La incertidumbre que generó la abundante moneda de cobre, desanimó o arruinó a los que no estaban preparados para hacer frente al aumento de los costes de transacción. Nicolo Balbi, uno de los asentistas más importantes de Felipe III, abandonó la negociación a partir de $1617^{13}$. En 1624 dos de los genoveses que sostenían las galeras de la escuadra de Génova, Giovanni Cambi y Jacome de Mari, quebraron al sufrir importantes pérdidas por firmar asientos con un cambio fijo del 3 por 100, cuando el premio suponía realmente un 50 por $100^{14}$. Otro de los efectos del vellón fue el rechazo de los banqueros a muchas de las consignaciones sobre las que tradicionalmente se negociaba el crédito. Mientras las Alcabalas, los Millones o la Cruzada empezaron muy pronto a recibir vellón, las consignaciones que recibían los banqueros sobre la Casa de la Contratación de Sevilla siguieron siendo en plata, pues esta institución recibía el metal precioso americano. Esto las convirtió en unas de las consignaciones más atractivas, y revalorizó

${ }^{12}$ Gelabert (1997) y (1998).

13 Sus operaciones de crédito con la Corona comenzaron en 1598 en Amberes. Grendi (1997), p. 63.

${ }_{14}$ Goodman (1997), p. 62. 
el papel que representó la llegada anual de las flotas en el sistema financiero de la Corona.

Esta distinción entre buenas y malas consignaciones fue un serio problema para la Real Hacienda, pues la obligó a ofrecer mayores garantías de devolución. El problema de la Corona durante el reinado de Felipe IV no fue sólo encontrar más dinero, sino encontrar fuentes de ingresos y mecanismos de pago que fuesen aceptados por sus banqueros. Todo ello suponía un encarecimiento indirecto de los servicios financieros o su reducción. Los banqueros podían ahora negarse a aceptar determinadas consignaciones sólo por suponer que serían pagados con una moneda que no les interesaba. Para procurar reducir su desconfianza se confió en medios empleados ya con anterioridad, y que consistían en incorporar a los banqueros a los órganos de gobierno de la Monarquía, o en solicitar sus servicios por vía de factoría ${ }^{15}$.

Al surgir el premio de la plata, la primera respuesta de la Corona consistió en prohibirlo. Sólo cuando comprendió que era imposible ignorarlo, trató de controlar su valor (Cuadro 1). Esta medida se enmarca en el contexto político de la Monarquía Absoluta, donde el gobierno establecía de forma arbitraria los precios máximos de muchos productos ${ }^{16}$. Fue lógico pensar que podía hacer lo mismo con el metal precioso. El establecimiento de un precio máximo oficial no pretendía tanto servir de referencia a los mercados, como desanimar las constantes expectativas de revalorización del metal precioso, forzando a la baja los contratos de cambio y eliminar los cambios especulativos. Los datos de premios publicados por Hamilton y Serrano Mangas demuestran claramente que, entre los particulares, el precio máximo apenas fue respetado. Sin embargo, el precio oficial no desapareció nunca. éTuvo éxito la Corona al negociar créditos en plata y pagarlos luego con moneda devaluada?

La teoría básica del control de precios describe los èfectos que se producen cuando se fuerza el precio de un producto por debajo de su precio de equilibrio. En esos casos, la cantidad demandada de ese bien es siempre mayor que la cantidad ofrecida, por lo tanto, la mercancía se agota rápidamente y hay un exceso de demanda ${ }^{17}$. Si no se establecen cupos, entonces los compradores compiten entre ellos para asegurar su acceso al producto. Esto provoca colas, y pérdidas de tiempo a los que esperan. Es decir, los consumidores, además de pagar el coste monetario que ahora

\footnotetext{
15 Ulloa (1977), pp. 137 y 145, y Álvarez Nogal (1999b), pp. 97-110.

16 Viñas y Mey (1968), pp. 715-772.

17 Friedman (1986), pp. 392-97, y Deacon and Sonsteli (1985), pp. 627-647.
} 


\section{CUADRO 1}

Premio máximo autorizado por la Real Hacienda para cambiar vellón por plata

\begin{tabular}{|c|c|}
\hline Fecha de la pragmática & Premio máximo permitido (porcentajes) \\
\hline $\begin{array}{l}8-3-1625 \ldots \ldots \ldots \ldots \ldots \ldots \\
27-3-1627 \text { al } 7-8-1628 \ldots \ldots . \\
30-4-1636 \ldots \ldots \ldots \ldots \ldots \ldots \ldots \\
5-11-1636 \text { al } 20-3-1637 \ldots \ldots\end{array}$ & $\begin{array}{l}10 \\
\text { Exención de premio máximo a las Diputaciones } \\
25 \text { hasta la llegada de las flotas, } 20 \text { después } \\
\text { Suspensión de la pragmática. Franquicias de } 28 \text { en } \\
\quad \text { algunas ciudades } \\
28 \\
50 \\
\text { Prohibición absoluta del premio } \\
50 \text { (al menos hasta } 1660 \text { ) }\end{array}$ \\
\hline
\end{tabular}

FUENTE: Hamilton (1984), pp. 93-96.

es más bajo, empiezan a pagar otros costes no monetarios, que normalmente suponen una mayor inversión de tiempo. Es lo que ha sido llamado por algunos autores «costes de transacción endógenos» ${ }^{18}$. Además, cuando la oferta del producto no es controlada por el Gobierno, tan sólo lo es su precio, surge un paralelo mercado ilegal o mercado negro. El equilibrio se consigue cuando esos costes de transacción igualan la diferencia entre el precio de la cantidad ofrecida en el mercado ilegal y el precio controlado. Entonces los consumidores usan indiferentemente los dos mercados, teniendo en cuenta el riesgo de ser castigados si son descubiertos incumpliendo la ley.

Este esquema teórico se puede aplicar perfectamente a lo que ocurrió en el mercado de plata castellana controlado por la Real Hacienda. En el mercado oficial aumentó la demanda de plata. Muchos trataron de conseguir el metal precioso a toda costa aunque no lo necesitasen, atraídos por las expectativas de revalorización y negocio a corto plazo. Manteniéndose invariable la oferta, pronto aparecieron las colas y los primeros indicios de escasez. La plata desapareció con rapidez del mercado, no porque hubiese menos, sino porque pasó rápidamente del mercado oficial al mercado negro. El hecho de que al precio regulado disminuyesen los oferentes de metal precioso, quizá porque esperaban que la regulación desapareciese

${ }^{18}$ Nguyen and Whalley (1986), pp. 290-300; Jones and Roemer (1987), pp. 12-13, y Grosse (1994), pp. 31-47. 
en el futuro o porque podían venderlo a precios más altos esquivando las pragmáticas, supuso también una mayor contracción de la oferta, agudizando el efecto de escasez.

Mientras el coste en tiempo no representó la diferencia entre el coste real y el coste nominal, la demanda de plata siguió creciendo y las colas aumentando, pues aún había margen de beneficio para soportar las pérdidas de tiempo. El nuevo equilibrio se consiguió cuando el coste en tiempo más el coste en dinero fue igual al coste real de la plata en términos monetarios. Sin embargo, ese equilibrio no se alcanzó en el antiguo precio real, sino en uno superior. De hecho, uno de los efectos de la regulación de precios es precisamente un incremento del precio real del producto regulado. A pesar de todos estos problemas, la Real Hacienda nunca renunció a intervenir en el sistema monetario, y continuó utilizando la moneda para financiar su gasto cuando no dispuso de ningún otro recurso. Así se sucedieron períodos de grandes acuñaciones de cobre con otros en los que se trató de eliminarlo bruscamente para evitar la inflación. Como telón de fondo, mantuvo siempre leyes que establecían el precio oficial de la plata y la amenaza de graves castigos a los infractores ${ }^{19}$.

\section{LA REAL HACIENDA NO APLICÓ EL PRECIO OFICIAL DE LA PLATA AL NEGOCIAR CON LOS BANQUEROS}

El estudio de los efectos de la regulación del precio de la plata es especialmente interesante en el caso de la relación entre los banqueros y la Real Hacienda, porque para ambas partes la plata era un bien insustituible. Los efectos descritos por la teoría en un mercado regulado son aún más intensos cuando la demanda resulta inelástica. La imposibilidad de financiar su gasto en el exterior con otro metal que no fuese plata, obligó a la Corona a conseguirla a cualquier precio, es decir, a acudir al mercado negro, allí donde se encontraba el metal precioso a su verdadero precio en términos de vellón. $\mathrm{Y}$ aunque resultase contradictorio, siguió manteniendo igualmente su política de regulación del premio. El mismo año en el que se promulgó el primer precio fijo oficial, las propias Cortes de Castilla habían solicitado su incremento hasta el 25 por 100, basándose

${ }^{19}$ Pellicer (1965). Aviso de 6 de marzo de 1640, p. 149. Aviso de 10 de septiembre de 1641 , p. 129 . Hubo castigos ejemplares. Hamilton (1984), p. 72. Desde febrero de 1627 la Inquisición se encargó de perseguir a los contrabandistas. 
en lo ineficaz y contraproducente que estaba resultando mantenerlo en el 10 por $100^{20}$. El propio Consejo de Hacienda advirtió a su Majestad de la ineficacia de luchar contra las fuerzas del mercado:

«las leyes en materia de moneda no tienen tanta fuerza quando no se conforman con el valor intrínseco de ellas» ${ }^{21}$.

Las pragmáticas incrementaron la incertidumbre que ya había generado la presencia del vellón. Si la Real Hacienda defendía el precio máximo y se firmaban las provisiones con ese límite en los cambios, los financieros sabían que a un 10 por 100 les sería difícil o casi imposible encontrar el metal precioso, y en cualquier caso sufrirían los costes no monetarios ya comentados. Esto forzó que algunos se negasen a prestar plata a cambio de vellón si no se les aseguraba el cambio de antemano. Lo que en realidad pretendían los hombres de negocios era poder acudir al mercado negro para efectuar los trueques, y después poder trasladar el coste real de ese cambio a la Real Hacienda.

La Corona tuvo que elegir entre hacer efectivo el decreto del precio máximo con todas sus consecuencias o seguir firmando asientos. Eligió la segunda opción porque era la que se amoldaba a sus intereses imperiales. Por lo tanto, aunque mantuvo las leyes de regulación, nunca las aplicó en la negociación crediticia con los banqueros. Ya durante el tiempo en el que la Corona se había resistido a reconocer la existencia de un premio, los banqueros recibieron compensaciones entre el 2 y el 5 por 100 en la firma de algunas provisiones. Sin embargo, esos porcentajes siguieron siendo insuficientes, porque al ser fijos les dejaban desprotegidos en el caso de que después siguiese subiendo el precio de la plata. En los años veinte, el valor del premio empezó a crecer con mayor intensidad y rapidez. Tal y como se ha comprobado, hasta 1623-1624 la oferta nominal de cobre estuvo sustituyendo a la oferta nominal de plata en circulación, por lo que no presionó sobre el precio del resto de los bienes, y el premio siguió siendo moderado, pero después de esa fecha se disparó la inflación. A ello contribuyó tanto la constante acuñación de cobre como la expansión de la deuda ${ }^{22}$. Esto hizo más difícil negociar premios fijos en la firma de las provisiones, y se produjo un endurecimiento en las posturas de los banqueros.

\footnotetext{
${ }^{20}$ Hamilton (1984), p. 95, nota 152.

${ }^{21}$ AGS, CJH, 622. Memorial del Consejo de Hacienda, sin fecha.

${ }^{22}$ García de Paso (2000a), p. 57, y (1999), pp. 2-4.
} 
Antonio Balbi fue uno de los primeros asentistas que se negaron a aceptar precios fijos oficiales en sus contratos. En 1623, antes de hacerse cargo de una provisión de 1.200 .000 escudos y ducados, exigió que la conversión de vellón a plata se ajustase según el precio real de mercado en el momento que necesitase cambiar la moneda. Aquel año, el Consejo de Hacienda no tuvo más remedio que aceptar esta condición, al no encontrar a ningún otro agente que pudiera asumir dicho crédito en mejores condiciones. Lógicamente, una vez hecha una excepción, el resto de los hombres de negocios exigió el mismo trato, y en similares términos se negociaron las Provisiones Generales de 1624 y 1625.

Para no tener que renunciar a su empeño de imponer un premio máximo, la Real Hacienda firmó los asientos con un premio relativamente bajo, similar al que exigía públicamente, pero después trató de compensar al banquero al margen de la negociación crediticia, o concediéndole permisos extraordinarios para que pudiese buscar el metal precioso en el mercado negro sin ser castigado por ello. Así, por ejemplo, en noviembre de 1631, Octavio Centurión firmó un asiento en el que se le concedió un premio del 15 por 100 , y a continuación se le dio permiso para trocar plata al precio que la encontrase ${ }^{23}$. El establecimiento de un precio ficticio en un contrato por debajo del precio real permitía negociar con otros poniendo como referencia ese precedente. De esta forma se concretaron precios de cambio en los contratos que no respetaban lo establecido en las pragmáticas, pero tampoco recogian el verdadero valor de la plata (Cuadro 2).

$\mathrm{El}$ que en el Cuadro 2 no aparezca ningún dato en algunos años responde a que no se dispone de ningún documento que confirme un determinado precio. Todos los datos sobre precios máximos y mínimos están respaldados al menos por la firma de un contrato. Algunas veces hay discrepancias de premios para un mismo año, dependiendo de la importancia del banquero, del mes en que se firme el asiento, etc. Ésa es la razón por la que se distingue entre el precio máximo y el mínimo. Cuando no hay un precio máximo, es que no hay discrepancias en la documentación disponible. Las tendencias mostradas en el Cuadro 2 ponen claramente de manifiesto que los precios negociados con los banqueros estuvieron más cerca de los precios reales que de los oficiales, sobre todo si tenemos en cuenta las compensaciones añadidas vía adehala o la concesión de privilegios y mercedes suplementarios. Además, como se confirma al final del período, la tendencia fue hacia la concesión del mismo precio del mer-

\footnotetext{
${ }^{23}$ AGS, CJH, 676. Consulta, 14 de noviembre de 1631.
} 


\section{CUADRO 2}

Precio de la plata en Castilla y en los contratos de crédito, 1617-1642

\begin{tabular}{cccccc}
\hline Años & $\begin{array}{c}\text { Precio } \\
\text { Real }\end{array}$ & $\begin{array}{c}\text { Precio } \\
\text { Oficial }\end{array}$ & $\begin{array}{c}\text { Precio } \\
\text { Mínimo }\end{array}$ & $\begin{array}{c}\text { Precio } \\
\text { Máximo }\end{array}$ & $\begin{array}{c}\text { Precio } \\
\text { compensado }\end{array}$ \\
\hline 1617 & - & 0,00 & 2,00 & - & - \\
1618 & 2,13 & 0,00 & 2,00 & - & - \\
1619 & 2,72 & 0,00 & - & - & - \\
1620 & 4,00 & 0,00 & 2,00 & - & - \\
1621 & 4,63 & 0,00 & 2,00 & - & - \\
1622 & 5,71 & 0,00 & 2,00 & - & - \\
1623 & 9,40 & 0,00 & - & - & - \\
1624 & 16,11 & 0,00 & 20,00 & 22,00 & - \\
1625 & 40,79 & 10,00 & 50,00 & - & - \\
1626 & 54,76 & 10,00 & - & - & - \\
1627 & 58,45 & 10,00 & - & - & - \\
1628 & 47,59 & 10,00 & 52,00 & - & - \\
1629 & 14,68 & 10,00 & 10,00 & - & - \\
1630 & 23,01 & 10,00 & 20,00 & 28,00 & 20,00 \\
1631 & 14,81 & 10,00 & 15,00 & - & - \\
1632 & 16,92 & 10,00 & 15,00 & - & - \\
1633 & 24,71 & 10,00 & 15,00 & - & - \\
1634 & 28,50 & 10,00 & 20,00 & - & - \\
1635 & 27,19 & 10,00 & - & - & - \\
1636 & 26,71 & 25,00 & 25,00 & - & - \\
1637 & 32,00 & 20,00 & - & - & - \\
1638 & 35,46 & 20,00 & 25,00 & 30,00 & - \\
1639 & 38,57 & 20,00 & 39,00 & - & - \\
1640 & 37,86 & 28,00 & 36,00 & 38,00 & precio de mercado \\
1641 & 77,59 & 50,00 & 34,00 & 50,00 & precio de mercado \\
1642 & 124,87 & 0,00 & - & - & - \\
\hline
\end{tabular}

FUENTES y NOTAS: Precio real: media anual del premio, Serrano Mangas (1996), p. 105; Precio oficial: Hamilton (1984), p. 95; Precio mínimo en los contratos: (AGS CJH 622, 628, 674, 676, 701, 713, 795, 828); Precio máximo en los contratos: (AGS CJH 622, 628, 701, 713, 795, 828); Precio compensado con la adehala: (AGS CJH 628, 656, 714, 795, 828).

cado. Esa libertad para acudir al mercado negro que inicialmente había sido excepcional, a partir de los años cuarenta se generalizó a casi todos los agentes con los que se negociaban créditos. Esto confirma también la debilidad en la que ya entonces se encontraba la Corona para negociar con sus agentes financieros. 
El precio máximo creado artificialmente con las pragmáticas sirvió sólo para justificar el precio impuesto por la Real Hacienda en los contratos en los que la otra parte no tenía medios para presionar. La Corona se convirtió en muy mala pagadora para quienes tenían una débil posición, demostrando cada vez más su falta de respeto hacia los derechos de propiedad en la actividad económica ${ }^{24}$. No ocurrió lo mismo con los banqueros, que podian negarse a seguir ofreciendo sus servicios financieros. Con ellos la Real Hacienda tuvo siempre una postura más flexible. Aunque la Real Hacienda intentó durante estos años suministrar a sus banqueros la mayor cantidad posible de metal precioso para evitar que acudieran al mercado negro, en muchas ocasiones fue imposible asumir todos los trueques, y no tuvo más remedio que acabar concediéndoles autonomía para practicar los cambios a través de lo que se llamó «licencia de trueque». El banquero se comprometía a buscar en el mercado negro suministradores de metal precioso, negociar libremente con ellos y trasladar después a las arcas reales el coste de esas operaciones «siempre con la bentaja que fuere posible en beneficio de la Real Hacienda» ${ }^{25}$.

Los hombres de negocios sólo tenían que presentar su relación jurada, indicando las cantidades que habían necesitado cambiar y su coste, sin necesidad de dar mayor información. Era importante no desvelar los mecanismos empleados para el trueque, ni las personas que intervenían en él. $\mathrm{El}$ intento por salvaguardar las fuentes que le habían permitido obtener plata era también una estrategia para asegurar los cambios en el futuro. Así pues, la Real Hacienda sospechó que muchas de esas operaciones tenían un componente claramente especulativo. De hecho, se sabía que había mucha gente que, sin necesidad de usar los metales preciosos, se dedicaba a buscar «plata para hacer negociación con ella» ${ }^{26}$. Una forma de evitar esas prácticas consistió en exigir mayor información sobre los cambios practicados, obligando a que la relación jurada incluyese también las personas y los precios de la reducción. También se intentó limitar la licencia de trueque tanto en el precio del cambio, como en la cantidad de dinero que podía cambiarse. Por ejemplo, en 1640 se prohibió a Maceo Maçey efectuar cambios por encima del 38 por 100, por lo que sólo pudo trocar una parte de lo que necesitaba. Unos meses después, el asentista solicitó un mayor margen para poder cumplir con sus provisiones, pero el Consejo de Hacienda se lo negó para no perjudicar las negociaciones que comen-

\footnotetext{
${ }^{24}$ Lo cual tiene implicaciones directas sobre el crecimiento económico. North (1990).

29 AGS, CJH, 828-1-28. Consulta, 30 de marzo de 1641.

${ }^{26}$ AGS, CJH, 622. Memorial sin fecha.
} 
zarían a partir del mes de mayo de 1641 con un importante grupo de hombres de negocios, pues en abril finalizaba el acuerdo que ese grupo tenía vigente sobre reducción de plata. Finalmente, Maçey logró un permiso para trocar 100.000 ducados más cargando sus gastos sobre la Real Hacien$\mathrm{da}$, pero tuvo que hacerlo en secreto y obligándose a dar cuenta frecuentemente de todas sus gestiones ${ }^{27}$. El problema era que un mayor número de controles dificultaba la agilidad que exigían los cambios, desanimando al hombre de negocios a comprometerse en créditos donde este tipo de operación era obligada. Además paralizaba la ejecución de las provisiones y reabría la negociación, cuando la Real Hacienda la daba ya por concluida. Controlar la especulación iba en detrimento de la expansión del crédito. Una vez más, la disyuntiva de siempre: mayor efectividad o dinero inmediato.

\section{LA ESTRATEGIA DE LOS AGENTES EN EL CONTEXTO DE LA REGULACIÓN}

Además del tiempo extra que fue necesario emplear para conseguir el metal precioso una vez regulado el mercado, uno de los costes más relevantes fue la incertidumbre que generó, al no tener nunca la seguridad de poder conseguir la plata en el momento preciso. Ese aumento del riesgo incentivó a los agentes económicos a adoptar estrategias que les permitiesen reducir la incertidumbre. Algunas de las alternativas que la teoría ofrece como consistentes en un escenario de control de precios consisten en llegar al mercado antes que el resto, o hacer frecuentes visitas para estar seguro de conseguir el producto deseado. Otra solución es la posibilidad de sobornar a los dueños del producto regulado o a los que controlan su distribución, con el fin de asegurarse el suministro ${ }^{28}$. En otros casos, alguien puede optar por controlar directamente los canales de distribución para estar seguro de que él y sus amigos pueden conseguir la cantidad que necesitan de esa mercancía. Es decir, las distorsiones del mercado generan un cambio en la actitud de los agentes, hasta encontrar de nuevo un equilibrio. $\mathrm{Y}$ si los productos no circulan libremente, tampoco es libre la actitud de los interesados. Podemos encontrar testimonios históricos de ese mismo comportamiento estratégico por parte de los agentes que aquí estudiamos.

${ }^{27}$ AGS, CJH, 828-1-28. Consulta, 30 de marzo de 1641.

${ }^{28}$ Friedman (1986), pp. 390-392. 
Tanto la Real Hacienda como los hombres de negocios trataron de eliminar parte de los costes no monetarios procurando asegurarse el acceso al metal precioso. Los financieros procuraron reducir cualquier posible riesgo de no poder cambiar el vellón que recibían en las consignaciones. Mientras que la Real Hacienda trató siempre de disponer del mayor volumen posible de metal precioso para no tener que plegarse a todas las exigencias de sus interlocutores en la negociación. Si se dominaba el mercado de plata o se disponía de una posición preferencial en los circuitos por los que circulaba el metal precioso, el hombre de negocios podía reducir mucho los costes que exigía el cambio o adelantarse al resto de competidores. La mayor parte de los banqueros solían cobrar sus consignaciones por las mismas fechas, siguiendo los ritmos propios de la recaudación. Por ejemplo, las libranzas situadas sobre el Servicio de Millones se pagaban en los meses de mayo y noviembre, lo cual incrementaba la demanda de cambios por esas fechas.

Algunos hombres de negocios procuraron acceder a cargos de responsabilidad en la propia Real Hacienda para afrontar los problemas monetarios con mayor holgura. Un claro ejemplo fue Julio Cesar Scazuola, agente en Castilla de la compañía «Conde Gerónimo Fucar y primo» y Tesorero General de la Santa Cruzada, una de las pocas rentas que aún recaudaban una parte en plata. El factor alemán aprovechó su cargo para retener en su beneficio el metal precioso, mientras forzaba a los acreedores de dicha renta a aceptar moneda de vellón. El Consejo de Hacienda advirtió en varias ocasiones que era necesario controlar a Scazuola para que, como tesorero general, pagase «tal como cobra, y no en otra moneda como le convenga» ${ }^{29}$. Las sospechas fueron confirmadas cuando, poco después, llegó a oídos del rey que Julio Cesar Scazuola también enviaba oro a los lugares donde el vellón corría ya cerca del 100 por 100 a finales de 1626 . Después cambiaba ese vellón en la Corte al premio oficial. Según el Consejo, era necesario advertir al hombre de negocios muy seriamente «por ser este caso, de mal ejemplo y perversa consecuencia» ${ }^{30}$. Esto nos explica también por qué algunos hombres de negocios aceptaron cargos en la Administración, o se afanaron por comprar oficios de responsabilidad, sobre todo aquellos relacionados con la gestión de determinadas rentas. No se trataba sólo de adquirir el prestigio de un título, sino de disfrutar de una posición privilegiada frente a sus competidores o de gozar de un margen de seguridad que el marco legal no ofrecía.

\footnotetext{
29 AGS, CJH, 634. Consulta, 1 de julio de 1627.

30 AGS, CJH, 621. Consulta, 16 de diciembre de 1626.
} 
Dentro de esta estrategia por acaparar las fuentes por las que circulaba el metal precioso, está la solicitud de muchos hombres de negocios a partir de los años treinta para cobrar sus consignaciones directamente en las cajas americanas, o en cualquier caso, antes de que el metal precioso llegase a la Casa de la Contratación de Sevilla ${ }^{31}$. Otra posibilidad consistió en acceder a las rentas donde se sabía con seguridad que circulaba el metal precioso, como fue el caso de la exportación de lana. Los asientos que firmó Andrea Pichinotti entre 1651 y 1656 son un buen ejemplo. En uno de ellos se comprometió a colocar 10.000 ducados en Venecia y 192.850 escudos en Amberes a cambio de que los arrendadores de lanas, puertos y diezmos le entregasen todo el metal precioso que recaudasen dichas rentas. Él les entregaría la misma suma en vellón más un 50 por 100 de premio ${ }^{32}$. Como, en el caso de la lana, los pagos se hacían con escrituras a distintos plazos, el factor genovés solicitó que le fuesen cedidas todas las escrituras firmadas a partir de su asiento ${ }^{33}$. Otra estrategia adoptada por los banqueros para defenderse de los premios abusivos que intentó imponer la Real Hacienda fue unirse entre ellos para plantear un frente común en la negociación del crédito. Una estrategia muy peligrosa para las pretensiones de la Corona. Los hombres de negocios exigieron las mismas condiciones en los cambios que las que se concedía a los factores o ministros del Rey a la hora de trocar plata en nombre de Su Majestad; es decir, impunidad para poder intervenir en el mercado negro. Entre sus principales quejas destaca la competencia desleal de la Real Hacienda, pues a pesar de prohibir el cambio salvo en las condiciones estipuladas por las pragmáticas, las arcas reales eran las primeras en buscar plata a precios reales de mercado ${ }^{34}$.

\section{CONCLUSIONES}

En este trabajo hemos pretendido mostrar los perjuicios que tuvo para la negociación crediticia la política monetaria de la Corona en torno al vellón. La existencia de una moneda cuyo valor resultaba difícil de determinar, incluso a corto plazo, influyó negativamente sobre las negociaciones

\footnotetext{
31 Álvarez Nogal (1999b), pp. 98-113.

32 AGS, CJH, 996. Asiento, 9 de marzo de 1652. Asiento con Andrea Pichinotti, 23 de febrero de 1656.

33 Sanz Ayán (1987), p. 204.

${ }^{34}$ AGS, CJH, 828. Memorial, 10 de septiembre de 1641.
} 
y sobre la capacidad y agilidad de la Corona para endeudarse. La Real Hacienda utilizó de forma indiscriminada las alteraciones monetarias para solucionar sus problemas financieros, hasta que la moneda se convirtió en un serio obstáculo para seguir negociando su crédito anual. Para no tener que pagar por ello un coste demasiado elevado, trató de imponer un precio máximo en el cambio vellón-plata. Esta medida no pretendía resolver el problema del vellón, sino mitigar los efectos inflacionistas del cobre que encarecian el crédito que necesitaba en el exterior. Su empeño por mantener un precio máximo provocó la aparición de dos tipos de mercado. Uno oficial, donde la Real Hacienda obligó a cambiar el metal precioso a quienes no pudieron eludir las pragmáticas y en el que siempre hubo escasez de plata. $Y$ otro paralelo, un activo mercado negro, donde el precio de las monedas fue el real, y en el que estuvieron presentes tanto los banqueros como la propia Corona.

Los banqueros plantearon diferentes estrategias para poder seguir negociando con la Corona sin sufrir los nocivos efectos de la moneda de cobre, tal y como predice la teoría. Si la Corona pudo seguir disfrutando de sus servicios financieros fue gracias a que no aplicó el precio máximo oficial cuando negoció con ellos, y pagó el metal precioso a su verdadero precio, aunque a veces lo hizo en términos no monetarios. Otro de los interesantes efectos que provocó el vellón fue la modificación de los contratos de crédito y la estrategia de los agentes económicos para acceder al metal precioso, lo cual alteró el funcionamiento de algunas de las tradicionales instituciones económicas castellanas como la Casa de la Contratación, y revalorizó las materias primas más demandadas en el exterior, como la lana.

No hemos tratado de cuestionar en estas páginas las razones de la Corona para controlar el precio del dinero, práctica común en el contexto de la Monarquía Absoluta y que afectó a otros ámbitos de la actividad económica. Lo relevante es que, independientemente de la mentalidad de la época y de las ideas económicas de un contexto social y cultural, el poder político fue incapaz de alterar las leyes del mercado y sacar beneficios. Al margen de todos los esfuerzos de regulación, en el mercado de crédito la Real Hacienda acabó pagando por la moneda de plata lo que realmente valía. Las pragmáticas no tuvieron efecto ni para detener la devaluación de la moneda de vellón, ni para hacer más barata la negociación con los hombres de negocios, y a la larga, tuvieron efectos más perniciosos tanto para la Corona como para la economía castellana. En primer lugar, porque las pragmáticas impidieron una regulación clara del precio de la plata, provocando mayores temores en el cumplimiento de los contratos, dificultades 
para recoger información, escasez de metal precioso en los mercados, etc. $\mathrm{El}$ aumento de la incertidumbre entre los agentes crediticios, repercutió en dudas, negociaciones más prolongadas y mayores exigencias de garantía para cumplir las provisiones que precisamente necesitaba la Corona. En segundo lugar, porque los efectos del precio máximo de la plata se hicieron sentir en el resto de la actividad económica, donde muchas veces también era imprescindible utilizar metal precioso. Y aquí no hubo privilegios ni excepciones. La escasez de plata, sin la garantía de la Corona para conseguirla, o con la amenaza de ser castigado si se hacía al margen de la ley, fue un problema añadido a los riesgos propios de la actividad empresarial castellana. A raíz de los males del vellón y de su equivocado planteamiento a la hora de solucionarlos, se incentivó el clientelismo y las estrategias ilegales.

\section{BIBLIOGRAFÍA}

Álvarez Nogal, C. (1997): Los banqueros de Felipe IV y los metales preciosos americanos (1621-1665), Madrid, Banco de España.

- (1999b): «Un comprador de oro y plata en la Sevilla del siglo XvII. Bernardo de Valdés al servicio de la Real Hacienda», en E. Vila Vilar y A. J. Kuethe (eds.), Relaciones de poder y comercio colonial, Sevilla, Escuela de Estudios Hispano-Americanos, pp. 85-115.

- (2000): «La estrategia de la Real Hacienda en la negociación del crédito de los Austrias», en A. M. Bernal (ed.), Dinero, moneda y crédito en la monarquia bispánica, Madrid, Fundación ICO-Marcial Pons, pp. 439-456.

Collantes, E., y J. P. Merino (1977): «Alteraciones al sistema monetario de Castilla durante el reinado de Carlos II», Cuadernos de Investigación Histórica, 1, pp. 73-98.

Deacon, R. T., y J. SONSTELI (1985): «Rationing by Waiting and the Value of Time: Results of a Natural Experiment», Journal of Political Economy, 93, 4, pp. 627-647.

Dominguez Ortiz, A. (1960): Politica y Hacienda de Felipe IV, Madrid, Editorial de Derecho Financiero.

Friedman, D. (1986): Price Theory, Cincinnati, South-Western Pub. Co.

Garcia de Paso, J. I. (1999): «The 1628 Castilian Crydown: A Test of Competing Theories of The Price Level», Madrid, Universidad Complutense (manuscrito).

- (2000a): «La estabilización monetaria en Castilla bajo Carlos II», Revista de Historia Económica, 18, 1, pp. 49-77.

- (2000b): «Expectations and Unsuccessful Monetary Reforms: The 1627-28 Castilian Deflationary Program», Madrid, Universidad Complutense (manuscrito).

GarCí GuerRA, E. M." (1999): Las acuñaciones de moneda de vellón durante el reinado de Felipe III, Madrid, Banco de España. 
Gelabert, J. E. (1997): La Bolsa del Rey, Barcelona, Crítica.

- (1998): «La evolución del gasto de la Monarquía Hispánica entre 1598 y 1650», Studia Historica. Historia Moderna, 18, pp. 265-297.

Goodman, D. (1997): Spanish Naval Power, 1589-1665, Cambridge, Cambridge University Press.

Grendi, E. (1997): I Balbi.Una famiglia genovese fra Spagna e Impero, Torino, Einaudi.

Grosse, R. E. (1994): «The Economics of Foreign Exchange Black Markets», en R. E. Grosse y C. Pechman, Foreign Exchange Black Markets in Latin America, Westport, Praeger Publishers, pp. 31-47.

Hamilton, E. J. (1983): El tesoro americano y la revolución de los precios en España, 1501-1650, Barcelona, Ariel.

- (1984): «Inflación monetaria en Castilla, 1598-1660», en El florecimiento del capitalismo, Madrid, Alianza, pp. 59-102.

Jones, C. W., y M. Roemer (1987): «Microeconomics of Price Controls: A Reexamination», Development Discussion Papers, Harvard University.

Miskimin, H. (1977): The Economy of Later Renaissance Europe, 1460-1600, Cambridge, Cambridge University Press

Motomura, A. (1994): «The Best and Worst of Currencies: Seigniorage and Currency Policy in Spain, 1597-1650», Joumal of Economic History, 54, 1, pp. 104-127.

- (1997): «New Data on Minting, Seigniorage and the Money Supply in Spain (Castile), 1597-1643», Explorations in Economic History, 34, pp. 331-367.

Nguyen, T. T., y J. Whalley (1986): «Equilibrium under Price Controls with Endogenous Transactions Costs», Journal of Economic Theory, 39, pp. 290-300.

NorTh, D. C. (1990): Institutions, Institutional Change and Economic Performance, Cambridge, Cambridge University Press.

PARKER, G. (1974): «The Emergence of Modern Finance in Europe, 1500-1730», en The Fontana Economic History of Europe: The Sixteenth and Seventeenth Centuries, Glasgow, pp. 520-615.

Pellicer, J. (1965): Avisos bistóricos, Madrid, Taurus.

Ruiz Martín, F. (1970): «La banca en España hasta 1782», en VVAA, El Banco de España. Una bistoria económica, Madrid, Banco de España, pp. 1-196.

- (1990): Pequeño Capitalismo. Gran Capitalismo. Simón Ruiz y sus negocios en Florencia, Barcelona, Crítica.

SANZ AyÁn, C. (1987): «La figura de los arrendadores de rentas en la segunda mitad del siglo XVII. La renta de las lanas y sus arrendadores», Hispania, 165, pp. 203-224.

- (1999): «Los procedimientos financieros: métodos y estrategias», en $E l$ oro y la plata de las Indias en la época de los Austrias, Madrid, Fundación ICO, pp. 588-590.

SerRano Mangas, F. (1996): Vellón y metales preciosos en la Corte del rey de España (1618-1668), Madrid, Banco de España.

SPOONER, F. C. (1972): The International Economy and Monetary Movements in France, 1493-1725, Cambridge, Harvard University Press. 
Sussman, N. (1993): «Debasements, Royal Revenues, and Inflation in France During the Hundred Years' War, 1415-1422», Journal of Economic History, 53, 1, pp. 44-70.

ULLOA, M. (1975): «Castilian Seigniorage and coinage in the Reign of Philip II», Journal of European Economic History, 4, pp. 459-477.

- (1977): La Hacienda Real de Castilla en el reinado de Felipe II, Madrid, FUE.

ViÑAS Y MEY, C. (1968): «Cuaderno económico-social de España de 1627-1628», Anuario de Historia Económica y Social, 1, pp. 715-72. 